\title{
Trade Policy Openness and Economic Performance: Cross-country Evidence
}

\author{
Dr. P N Weerasinghe
}

\begin{abstract}
There is a lack of strong empirical evidence on the relationship between open trade policies and economic performance largely due to problems associated with the measurement of trade policy openness. This paper uses a new measure of trade policy openness along with other available measures in the literature to test the robustness of the relationship using a large cross-country data set .It was found that an increase in openness by ten percentage points would raise growth in output per worker by 0.6 percentage points annually. Of this contribution, almost half of influence operates through improvements in total factor productivity, while the other half operates through accumulating physical and human capital. The contribution of openness to growth via physical capital accumulation is about twice as large as the contribution via human capital accumulation. (JEL F19, O24)
\end{abstract}

\section{Introduction}

The impact of open trade policies on economic performance has been vigorously debated in the literature during the past few decades. In theory, static welfare gains from more open trade policies have been understood and well documented in the theoretical literature. With the development of endogenous growth theory, there is some provision for equilibrium growth models to incorporate trade policy variables in explaining the long-run rate of growth, as well as the level of per capita real income. In addition, multilateral institutions such as The World Bank and International Monetary Fund (IMF) seem to have reached a consensus that open trade policies help promote economic growth. These institutions have started to impose trade liberalization programs as conditions for loans to developing countries. However, empirical work still suffers from serious limitations, and therefore does not provide completely robust evidence on the relationship between trade policy openness and economic performance. For example, a growing number of cross-country studies attempting to support open trade policies have been evolving in the literature ${ }^{1}$. Most notably, Sebastian Edwards produced a series of cross-country studies providing evidence of a positive and robust relationship between trade openness and economic growth. On the other hand, skeptics of open trade policies continue to argue against these findings. The criticisms have been based on two major grounds.

First, the serious measurement problems associated with the indicators of trade policy used in cross-country studies. Rodrik and Rodriguez (1999) argues along these lines critically reviewing four of the major studies that support a positive relationship and highlight- 
ing the problems associated with them. They critically reviews four of these studies, namely Dollar (1992), Ben-David (1993), Sachs and Warner (1995) and Edwards (1998). Rodrik and Francisco (1999) concludes:

In many cases, the indicators of "openness" used by researchers are poor measures of trade barriers or are highly correlated with other sources of bad economic performance. In other cases, the methods used to ascertain the link between trade policy and growth have serious shortcomings... We find little evidence that open trade policies-in the sense of lower tariff and non-tariff barriers to trade-are significantly associated with economic growth.

Second, a source of inconsistent results is the estimation of total factor productivity growth (TFPG) rates used in cross-country studies. Different studies use different methodologies to estimate their own TFPG rates for similar groups of countries. Differences arise because of problems associated with the measurement of factor inputs and factor shares for large group cross-country studies. Edwards (1998), Bosworth and Collins (1996), Bosworth, Collins and Chen (1996), Nehru and Dhareshwar (1994), and The World Bank (1993) have estimated alternative TFPG rates for a similar group of countries. Methodological differences and some differences in data sets have produced significantly different estimates of TFPG rates. As a result, there has been a serious debate about TFPG rates in some East Asian countries. The differences in TFPG rates appeared to be one of the reasons for producing inconsistent results on the relationship between TFP growth and trade openness measured in terms of similar indicators. For example, Edwards (1998) found a positive relationship between some direct indicators of trade openness and TFP growth, whereas using similar indicators, Bosworth and Collins (1996) found no significant relationship. Weerasinghe and Fane (2005) examines the discrepancies of TFP growth estimates among few studies in the literature and identifies the sources of discrepancies. They argue that the best available estimates for a large group of countries are those of Weerasinghe (1999) and Bosworth and Collins (1996). On that basis, this paper uses the TFPG rates for a large group of countries from Weerasinghe (1999).

In view of the above problems associated with measurements of openness and TFPG rates, it is not surprising that empirical studies have produced some inconsistent results and that the debate is far from over. Therefore, this study is aimed mainly at testing the empirical relationship between trade policy openness and economic growth, and surveying the robustness of the findings. In view of problems associated with the measurement of trade policy openness, this paper introduces an alternative indicator based on the concept called anti-trade bias for a large group of countries. This indicator along with other available indicators of trade openness in the literature is used to test the relationship between trade policy openness and economic performance. The methodology used in this paper is similar to the methodology used by Bosworth and Collins (1996) to test the same relationship. They focused research into a new direction by measuring the impact of trade openness on output growth through its major components, namely capital accumulation and TFP growth.

1/ Edwards (1992), Edwards (1993), Dollar (1992), The World Bank (1993), Edwards (1998) 
This paper uses a more comprehensive set of trade policy indicators to examine the impact of trade openness on output through different sources of growth.

This paper takes the research in another direction, by testing the relationship in short, medium and long term. To test the relationship in the short term, annual time series data on different sources of growth and trade openness are used in panel data regressions. For medium and long term relationships, the period averages are used in pure cross-country growth regressions. In fact, almost all of the previous studies have tested the relationship in either the long or medium term. To our knowledge, Harrison (1996) is the only study which tested the relationship between GDP growth and a few alternative indicators of trade openness on the basis of annual time series data. Harrison found the relationship was stronger in the short term. A lesser number of alternative indicators have been significant in long-term growth regressions. Using a more comprehensive data set, this study also tests whether there is a difference between short and long term relationships.

Accordingly, this study mainly addresses three issues. First, using some of the available indicators and a new indicator based on the anti trade bias, the relationship between alternative measures of openness and economic growth is tested. Implications can then be drawn on the basis of each indicator's strengths and weaknesses. Because there is some evidence in the literature that the relationship is different between the short and long term, the relationship is then tested for different time periods, namely short, medium and long term,.

Finally, as the existing evidence in the literature about the channels through which trade openness operates to affect output growth is not conclusively established, the impacts of trade openness on output growth through the other two sources of growth, namely physical capital accumulation and human capital accumulation, are also measured. This procedure also allows calculation of the total impact of trade openness on output growth through alternative sources of growth. Section two briefly explains the model and methodology; section three explains the data; and section four presents the results of the econometric regressions.

\section{The model and methodology}

To disaggregate GDP growth into three major sources, namely economy wide TFP growth, physical capital accumulation and human capital accumulation, two aggregate inputs are distinguished in the production process, namely physical capital and skill adjusted labor. Constant returns to scale over these two factors of production are also assumed. The data set on labor measures the number of persons in the labor force. To measure the number of skill adjusted labor units in the production process, it is necessary to differentiate the skill level of individuals in the labor force. A skill function has been introduced for this purpose: a person with $H$ years of formal education is assumed to provide $g(H)$ units of effective labor inputs. While skill levels of labor may depend on several factors, such as education, experience, and age, the only form of information available for a large group of countries is data on education. Hence the skill function is defined as a function of the average years of schooling per person. The aggregate production function used is of the following form. 


$$
Y_{t}=F\left(A_{t}, K_{t}, L_{t}\right)
$$

$K_{t}$ - physical capital stock

$L_{t}-$ effective aggregate labor input

$A_{t}$ - total factor productivity

$$
L_{t}=N_{t} g\left(H_{t}\right)
$$

$N_{t}$ - number of persons in the labor force

$H_{t}$ - average years of formal education per person in the labor force $g\left(H_{t}\right)$ - effective labor input per person in the labor force.

Differentiating equation (1) with respect to time and ignoring the subscript $t$ :

$$
\frac{d Y}{Y}=\frac{F_{A} d A}{Y}+\varepsilon_{K} \frac{d K}{K}+\varepsilon_{L} \frac{d L}{L}
$$

where $\varepsilon_{K}=\frac{K}{Y} \frac{\partial F}{\partial K}, \varepsilon_{L}=\frac{L}{Y} \frac{\partial F}{\partial L}$ and $F_{A}=\frac{\partial F}{\partial A}$

$S_{K}=\frac{c K}{p Y}$ and $S_{L}=\frac{w L}{p Y}$ where $p, c$ and $w$ are price of output, rental on capital and wage levels, respective ly. $S_{K}$ and $S_{L}$ are the shares of capital and labor, respective ly.

If $c=p \frac{\partial F}{\partial K}$ and $w=p \frac{\partial F}{\partial L}$ then $\varepsilon_{K}=S_{K}$ and $\varepsilon_{L}=S_{L}$

In other words, if inputs are paid their values of marginal products, elasticities of output with respect to inputs can be measured in terms of shares of inputs $\left(S_{K}\right.$, and $\left.S_{L}\right)$. Hence, equation (3) can be rewritten in the form of $\log$ differences.

$d \log \left(Y_{t}\right)=\theta d \log \left(A_{t}\right)+S_{K} d \log \left(K_{t}\right)+S_{L} d \log \left(L_{t}\right)$

Substituting skill adjusted labor $(L)$ with its specification in equation (2), and rearranging the above equation, growth in output per worker can be divided into its three major components as below.

$$
\left\{d \log \left(Y_{t}\right)-\operatorname{dlog}\left(N_{t}\right)\right\}=\theta \operatorname{dlog}\left(A_{t}\right)+S_{K}\left\{d \operatorname{dog}\left(K_{t}\right)-\operatorname{dlog}\left(N_{t}\right)\right\}+S_{L} \operatorname{dlog}\left\{g\left(H_{t}\right)\right\}
$$

TFPG is defined as the first component of the right hand side in the above equation. The second component of the right hand side of the equation can be interpreted as the contribution of physical capital accumulation, while the third component is the contribution 
of human capital in output growth per worker. These three components are formally defined by the following set of equations.

$$
\begin{aligned}
& Y=Y_{A}+Y_{K}+Y_{H} \\
& y=d \log \left(Y_{t}\right)-d \log \left(N_{t}\right) \\
& y_{A}=\theta d \log \left(A_{t}\right) \\
& y_{k}=S_{K}\left\{d \log \left(K_{t}\right)-d \log \left(N_{t}\right)\right\} \\
& y_{H}=S_{L} d \log \left\{g\left(H_{t}\right)\right\}
\end{aligned}
$$

The first exercise in this chapter is to test the relationship between TFPG and various measures of trade openness. To that end, a general form of regression equation is derived for annual time series data.

$$
y_{A_{i i}}=\lambda+\varphi O P E N_{i t}+\gamma \frac{Y_{i t-1}^{\max }}{Y_{i t-1}}+\mu \frac{H_{i t-1}^{\max }}{H_{i t-1}}+e_{i t}
$$

$\mathrm{Y}_{\mathrm{it}-1}$ - real GDP per capita in year $\mathrm{t}-1$ for country $\mathrm{i}$.

$\mathrm{H}_{\mathrm{it}-1}$-average years of schooling per person in year $\mathrm{t}-1$ for country $\mathrm{i}$.

$\mathrm{OPEN}_{\mathrm{it}}$ - a proxy for trade openness

$\mathrm{e}_{\mathrm{it}}-$ residuals

\section{$\lambda$ - constant}

Two variables to represent relative values of real GDP per capita and education have been included in the regression to capture initial conditions of countries. Choice of two initial conditions is based purely on past empirical evidence. There is strong empirical evidence on the relationship between economic growth and the initial levels of GDP and education. The rationale for the introduction of initial conditions is based on the concept called the conditional convergence hypothesis in which, all other things being equal, the countries with different initial levels of initial income and education are expected to grow at different rates to catch up with the other countries.

To derive pure cross-sectional regressions from the above regression equation, variables for TFPG and openness are replaced with their average values over longer time periods. Variables for initial conditions are replaced with the values of initial conditions at the beginning of the time period. Hence, the general form of cross-sectional regression equation can be written as follows. 


$$
y_{A_{i}}=\lambda+\varphi O P E N_{i}+\gamma\left[\frac{Y_{I}^{\max }}{Y_{I}}\right]_{i}+\mu\left[\frac{H_{I}^{\max }}{H_{I}}\right]_{i}+u_{i}
$$

\section{$\mathrm{y}_{\mathrm{A}}-$ Average rate of TFP growth over the period for country $\mathrm{i}$}

$O P E N_{i}$ - A measure of trade openness averaged over the period

$Y_{I}$ - Real GDP per capita in the initial year

$H_{I}$ - Average years of schooling per person in the initial year

$Y_{I}^{\max }, H_{I}^{\max }$ - maximum values of $Y_{I}$ and $H_{I}$ respectively

The period covered in any regression depends on the proxy for trade openness in the regression because alternative proxies cover different time periods. For example, the indicators based on the black market premium and the Sachs-Warner index are the only ones to cover the full time period. All other indicators cover sub-periods.

Finally, a similar set of regression equations is used to measure the impact of trade openness through the other sources of growth. To test that relationship, the dependent variable of the above regression is replaced with growth rates of the other sources, namely physical capital accumulation and human capital accumulation. The general form of regression for this set is given below.

$$
f_{i}=\lambda+\varphi \operatorname{OPEN}_{i}+\gamma\left[\frac{Y_{I}^{\max }}{Y_{I}}\right]_{i}+\mu\left[\frac{H_{I}^{\max }}{H_{I}}\right]+u_{i}
$$

The above regression equation generates all cross-country growth regressions replacing the dependent variable with alternative sources of growth, and by replacing the proxy for trade openness with the alternative indicators of trade openness given in Appendix 1. Formally, this set of regression equations can be written in the following manner.

$$
f_{i}=X \beta_{j}+u_{j}
$$

$f_{i}$ - data vectors of average growth rates of any sources of growth

$X$ - matrix of explanatory variables $\left(1, O P E N, \frac{Y_{I}^{\max }}{Y_{I}}, \frac{H_{I}^{\max }}{H_{I}}\right)$

$\beta_{\mathrm{j}}=\left(\lambda_{\mathrm{j}} \varphi_{\mathrm{j}} \gamma_{\mathrm{j}} \mu_{\mathrm{j}}\right)$ where $\mathrm{j}=\mathrm{A}, \mathrm{K} . \mathrm{H}$

For each set of explanatory variables, there will be three vectors of estimated coefficients for the three components of growth in dependent variables. Each vector of coefficients estimates the impact of explanatory variables on the output growth through each component of growth. These estimates allow examination of the effect of trade openness on 
output growth through three major sources of growth. In addition, the computational identity specified in equation (5) allows these three vectors of estimated coefficients to be added to derive the total impact of trade openness on growth in output per worker. In matrix form:

$$
\begin{aligned}
& y=X \beta_{\Sigma}+u_{\Sigma} \\
& \text { where } \beta_{\Sigma}=\sum_{j=A}^{H} \beta_{j} \text { and } u_{\Sigma}=\sum_{j=A}^{H} u_{j} \quad j=(A, K, H)
\end{aligned}
$$

Using this computational identity, the total estimated effect of trade openness on growth in output per worker is calculated.

\section{Data}

Data for dependent variables of all regressions come from Weerasinghe (1999) where the estimated annual growth rates of three major components in output growth per worker have been estimated based on the growth accounting framework explained above. Average growth rates over the period 1961-90 are reported in Appendix Table 1. There are two alternative sets of estimates of TFP growth: a) the estimates based on education data from Nehru and Dhareshwar (1994) for the period 1960-87, b) the estimates based on education data from Barro and Lee (1996) for the period 1960-90. Annual time series estimates of sources of growth, particularly TFPG and human capital accumulation, cannot be calculated from the Barro and Lee data set, because it provides time series data on education only at five-year intervals. Therefore, the estimates of sources of growth based on the Nehru and Dhareshwar data set are used in the panel data regressions involving annual time series data. Accordingly, panel data regressions cover the sub-period 1960-87. Two data sets on education have generated significantly different estimates of TFPG growth rates for some countries due to differences on education data in two data sets.

The cross-sectional regressions use growth estimates based on the Barro and Lee data set, averaged over the periods 1960-90 and 1970-90 in long term growth regressions. The time period depends on the measure of trade openness used in alternative regressions. The medium term growth regressions cover ten-year periods, because some proxies measure cross-country variations in trade openness only for sub-periods. If data are available for more than one ten-year period, the average values are pooled in the medium-term growth regressions to raise the degree of freedom.

Data for the proxies of trade openness come from Weerasinghe (1999), where information has been collected on ten different indicators of trade policy and explained in detail the ways these indexes have been constructed. A brief description of alternative measures of trade openness is given in Appendix 1. All of the proxies for trade openness have been scaled in a way that all proxies have unit standard deviation and zero mean. This scaling allows the measurement of all alternative indicators in standard deviation units so that all would have a common interpretation otherwise measured in very different units. The scaling 
factors can be used to relate the results with non-scaled measures to draw implications on policy matters. All indicators have also been defined to be indicators of openness. Accordingly, if a country moves to a more open trade regime, values of the indicator are expected to increase, so that a positive estimated coefficient indicates a positive relationship between trade openness and growth.

Annual time series data are available only for two measures of trade openness: 1) a proxy based on the black market premium (INV-BMP), and 2) a trade-bias index (TBI), which is based on the concept called anti-trade bias. Annual time series data on TBI are available only for a group of 38 countries from the year 1970. There are missing observations for some countries for the period between 1970-90. Hence the total number of observations available for the panel data regression involving TBI is limited to around 500. However for the INVBMP, the available number of observations exceeds 2000.

For pure cross-country growth regressions, most of the available indicators of trade openness cover sub periods between 1960-90. In these situations, the other variables of the regression equations are also changed to cover similar time periods, by introducing average growth rates of shorter time periods and the initial conditions of those sub-periods. For example, the trade openness index in Leamer (1988) measures trade openness for the year 1982. Hence this index is used with the average growth rates over the period 1980-90, instead of the average growth rates over the full time period 1961-90. Most direct indicators, such as levels of tariffs and quantitative restrictions, measure cross-country variations of trade openness for the periods in the late 1980s. Hence these indicators are used only in the medium term growth regressions over the period 1980-90. In these regressions, initial conditions also cover the first year of the sub-period instead of the year 1960. In these kinds of empirical studies in the literature, indicators of trade policy covering the mid or late 1980s have been used to explain the variation of growth rates over the period 1960-90. It is unlikely that the stances of trade policies in the late 1980s are good predictors of trade policies in the 1960s and 1970s. In most countries, trade policies changed considerably over this time period, so that the use of such indicators may produce some misleading results. Therefore, long term growth regressions use only three proxies of trade openness, namely the SachsWarner index (SWI), the inverse black market premium (INV-BMP) and the trade bias index (TBI). Average values of the SWI and the INV-BMP cover the full time period, while the TBI covers the period 1970-90 for a sub-sample of countries. All the other proxies of trade openness are included in growth regressions covering the period of 1980-90.

Data for initial conditions come from two sources. Initial levels of real GDP per capita come from the Barro and Lee data set. The primary source of this data is Penn World Tables while initial levels of education data come from Nehru and Dhareshwar (1994) in panel data regressions. In pure cross-sectional regressions, initial education data come from the Barro and Lee data set, to be consistent with the growth estimates. From this information, initial levels of real GDP and education relative to that of the United States are calculated, because the US has the maximum levels of GDP and education during most of the period under study. 


\section{Results}

\section{A. TFP growth and trade openness}

\section{Long term growth regressions}

Table 1 reports the results of cross sectional TFPG growth regressions in which dependent variables are annual TFP growth rates averaged over the periods 1960-90 and 1970-90, and measured in percentage rates. Explanatory variables are alternative indicators of trade openness and relevant initial conditions. The three alternative indicators of trade openness are the trade bias index (TBI), the inverse black market premium (INV-BMP) and the SachsWarner index (SWI). The TBI is averaged over the period 1970-90 while the INV-BMP and the SWI cover the period 1960-90. All the other available indicators cover shorter time periods and so are not used to explain variations in long-term TFPG rates. In the analysis of alternative indicators of trade openness, the trade bias index (TBI) is a direct measure of trade openness, which is significant in the first regression.

\section{Table 1 - Long term TFP growth regressions: Average annual percentage growth rates}

\begin{tabular}{|c|c|c|c|}
\hline & (1) & (2) & (3) \\
\hline & $70-90$ & $60-90$ & $60-90$ \\
\hline$H_{1}^{\max } / H_{l}$ & $\begin{array}{l}-0.147 \\
(-1.30)\end{array}$ & $\begin{array}{c}-0.107^{\star * *} \\
(-3.66)\end{array}$ & $\begin{array}{c}-0.067^{* *} \\
(-2.21)\end{array}$ \\
\hline$Y_{1}^{\max } Y_{1}$ & $\begin{array}{c}0.117^{* * *} \\
(2.82)\end{array}$ & $\begin{array}{l}0.019 \\
(1.35)\end{array}$ & $\begin{array}{c}0.050^{* * *} \\
(2.72)\end{array}$ \\
\hline$T B I$ & $\begin{array}{l}0.331^{*} \\
(1.83)\end{array}$ & & \\
\hline$I N V-B M P$ & & $\begin{array}{c}0.395^{\star \star \star} \\
(3.24)\end{array}$ & \\
\hline SWI & & & $\begin{array}{c}0.635^{\star \star * *} \\
(4.57)\end{array}$ \\
\hline Constant & $\begin{array}{l}-0.717 \\
(-1.92)\end{array}$ & $\begin{array}{c}0.651^{\text {***}} \\
(3.43)\end{array}$ & $\begin{array}{l}0.181 \\
(0.90)\end{array}$ \\
\hline$R$-square & 0.10 & 0.35 & 0.34 \\
\hline$N$ & 37 & 68 & 75 \\
\hline
\end{tabular}

Notes:

1. $t$-ratios of regression coefficients are given in parentheses and statistical significance of coefficients is denoted as: $* * * 1 \%$, **5\%., *10\%

2. $\quad N$ - number of observations

3. TBI,INV-BMP and SWI have been scaled so that all have zero mean and unit standard deviations. Mean values of non-scaled TBI, INV-BMP and SWI are -12,-35 and 41 and standard deviations are 9,62 and 45 percentages respectively. 
This result implies that increasing openness in terms of TBI by one standard deviation from its mean appears to raise long term TFPG growth by 0.3 percentage points annually. Since all indicators of trade openness have been scaled so that all have mean zero and unit standard deviation, the impact of each indicator on growth rates can be compared with each other.

In terms of increases in openness by standard deviation units, openness measured by SWI has the highest impact on TFP growth and TBI the lowest. However, the result is not necessarily in the same order in terms of original measures. For example, an increase in scaled TBI by one standard deviation requires an increase of about 9 percentage points in the original measure of TBI, i.e., before scaling. Therefore an increase in non-scaled TBI, from -20 percent to -10 percent, for example, would raise annual TFP growth by 0.36 percentage points.

Similarly, the standard deviation of non-scaled BMP is about 60 percentage points. Therefore a 60 percentage point reduction in BMP would raise scaled INV-BMP by one unit and annual TFP growth by 0.4 percentage points.

Note that the standard deviation of non-scaled INV-BMP is about six times as large as the standard deviation of non-scaled TBI, whereas the coefficient in scaled INV-BMP in Table 1 is only slightly larger than that of scaled TBI. Accordingly, a ten percentage point reduction in non-scaled TBI raises annual TFP growth by 0.36 percentage points, whereas a ten percentage point reduction in non-scaled BMP would only raise TFP growth by 0.06 percentage points.

In terms of the categorical indicator, Sachs-Warner index (SWI), an increase in scaled SWI by unit standard deviation requires a country's number of open years during the period to be increased by 45 percent. For example, if a country with a closed trade regime throughout the 30-year period had been open for around half of that period, it could have raised TFP growth by 0.6 percentage points annually. However, due to differences in measured units, the impact of non-scaled SWI on TFP growth is difficult to compare with the impact of the others.

In all long-term growth regressions, both initial conditions have expected signs and are highly significant in most situations. Overall explanatory power in terms of R-square statistics is also satisfactory in two regressions, given the fact that only one policy variable has been introduced to explain cross-country variations in TFP growth rates.

The result is consistent with other studies, in the sense that all studies have found that measures based on both the Sachs-Warner index of openness and the black market premium are significantly correlated with economic growth rates with the expected signs. However, the results in the literature have not been consistent with regard to the relationship between direct indicators of trade openness and economic growth rates, particularly in terms of tariffs and quantitative restrictions. The findings in relation to the TBI indicate that the relationship is robust with direct indicators as well. In fact, the TBI takes both import and export taxes into account in measuring trade openness, whereas all the other available direct measures take amount of only one form of trade restriction at a time. Sachs and Warner (1995) defined their index in order to take four different forms of trade restriction into account. However, the categorical nature of their index raises doubts about its reliability. In fact, the 
dominant factor which determines a country's openness in the Sachs-Warner index is the black market premium. There is significant evidence in the literature that the black market premium is highly negatively correlated with economic growth rates. The findings of the present study strongly support this view. Hence, SWI may mostly reflect the variations of BMP, which produces this highly significant relationship. It is however difficult to make strong implications in relation to trade openness from the relationship between BMP and economic growth, because high black market premiums may result from some policies other than trade restrictions. Nevertheless, empirical evidence suggests that trade restrictions are positively correlated with BMP, justifying its use as a proxy for trade openness. The results in this study in relation to TBI suggest that trade openness has a significant positive impact on long term productivity improvements. This measured impact is much higher than that in terms of INV-BMP.

\section{Medium term TFPG growth regressions}

In medium term growth regressions, the dependent variable was ten-year averages of TFP growth rates. Proxies for trade openness also cover corresponding time periods or subperiods within the ten-year period. For some indicators of trade openness, data are available for more than one ten-year period. In these situations, data have been pooled to raise the degree of freedom in the regressions. Variables for initial conditions have also been pooled to represent the initial year of respective sub-periods. For example, the regressions involving INV-BMP, SWI, TBI cover more than one ten-year period. All the other regressions cover the period 1980-90, because data on these measures of trade openness are only available for this period. Table 2 reports the results.

The results in the first three columns of Table 2 indicate that the relationship between TFPG and trade openness is robust in terms of TBI, INV-BMP and SWI. These three variables were also highly significant in the long-term growth regressions. The estimated coefficients of trade openness are slightly higher in the medium term growth regressions than for the long-term growth regressions. For example, an increase in one standard deviation in INVBMP would raise medium term TFP growth by 0.8 percentage points annually, compared with 0.4 percentage points in the long term. However, the standard deviation of medium term nonscaled INV-BMP was about 90 percentage points, whereas the standard deviation of long term non-scaled INV-BMP was about 60 percentage points. The main effect of this difference is a significantly higher coefficient for INV-BMP in the medium term growth regressions. There is however no significant difference in non-scaled coefficients. For example, a 10 percentage point reduction in medium term non-scaled BMP would raise medium term annual TFP growth by 0.08 percentage points, compared with a 0.06 percentage points increase shown in the long term growth regressions. The coefficients of both TBI and SWI are also slightly higher in a similar order.

However, the other direct indicators of trade openness in medium term growth regressions are not at all significant in explaining cross-country variations in TFPG. For example, the results in columns (4), (5), (6) and (7) of Table 2 involve indicators measured in terms of some form of tariffs or quantitative restrictions; all are not only insignificant but also have negative signs. All the indicators have been defined in such a way that a positive relationship between the trade openness and growth should return a positive coefficient in the 
Table 2 - Medium term TFP growth regressions: Average annual percentage growth rates

\begin{tabular}{|c|c|c|c|c|c|c|c|c|c|c|c|}
\hline & (1) & (2) & (3) & (4) & (5) & (6) & (7) & (8) & (9) & (10) & (11) \\
\hline $\mathrm{H}_{1}^{\max / H_{1}}$ & $\begin{array}{l}-0.255^{\star \star} \\
(-2.15)\end{array}$ & $\begin{array}{l}-0.038 \\
(-0.81)\end{array}$ & $\begin{array}{l}0.006 \\
(0.14)\end{array}$ & $\begin{array}{l}-0.357^{\star *} \\
(-2.08)\end{array}$ & $\begin{array}{l}-0.357 \\
-(-2.06)\end{array}$ & $\begin{array}{l}-0.160 \\
(-0.79)\end{array}$ & $\begin{array}{l}-0.125 \\
(-0.61)\end{array}$ & $\begin{array}{l}0.024 \\
(0.23)\end{array}$ & $\begin{array}{l}-0.946 \\
(-1.66)\end{array}$ & $\begin{array}{l}0.151 \\
(0.31)\end{array}$ & $\begin{array}{l}-0.209 \\
(-1.44)\end{array}$ \\
\hline$Y_{1}^{\max } / Y_{1}$ & $\begin{array}{l}0.174^{\star \star \star} \\
(3.25)\end{array}$ & $\begin{array}{l}0.020 \\
(0.73)\end{array}$ & $\begin{array}{l}0.031 \\
(1.06)\end{array}$ & $\begin{array}{l}0.069 \\
(1.22)\end{array}$ & $\begin{array}{l}0.071 \\
(1.28)\end{array}$ & $\begin{array}{l}0.119^{* *} \\
(2.20)\end{array}$ & $\begin{array}{l}0.097 \\
(1.57)\end{array}$ & $\begin{array}{l}-0.040 \\
(-0.70)\end{array}$ & $\begin{array}{l}0.107 \\
(1.00)\end{array}$ & $\begin{array}{l}-0.136 \\
(-0.79)\end{array}$ & $\begin{array}{l}0.066 \\
(1.34)\end{array}$ \\
\hline $\mathrm{TBI}$ & $\begin{array}{l}0.516^{* *} \\
(2.13)\end{array}$ & & & & & & & & & & \\
\hline INV-BMP & & $\begin{array}{l}0.800^{\star *} \\
(2.29)\end{array}$ & & & & & & & & & \\
\hline SWI & & & $\begin{array}{l}0.762^{* * *} \\
(4.39)\end{array}$ & & & & & & & & \\
\hline INV-OWTI & & & & $\begin{array}{l}-0.054 \\
(-0.16)\end{array}$ & & & & & & & \\
\hline INV-OWQI & & & & & $\begin{array}{l}-0.003 \\
(-0.00)\end{array}$ & & & & & & \\
\hline INV-AVGT & & & & & & $\begin{array}{l}-0.366 \\
(-1.17)\end{array}$ & & & & & \\
\hline INV-NTB & & & & & & & $\begin{array}{l}-0.323 \\
(-0.89)\end{array}$ & & & & \\
\hline INV-MTAX & & & & & & & & $\begin{array}{l}0.035 \\
(0.17)\end{array}$ & & & \\
\hline INV-TRI & & & & & & & & & $\begin{array}{l}-0.990 \\
(-1.69)\end{array}$ & & \\
\hline LEAMER & & & & & & & & & & $\begin{array}{l}0.226 \\
(0.63)\end{array}$ & \\
\hline INV-DOLLAF & & & & & & & & & & & $\begin{array}{l}0.352 \\
(1.35)\end{array}$ \\
\hline Constant & $\begin{array}{l}-0.830^{*} \\
(-2.14)\end{array}$ & $\begin{array}{l}0.229 \\
(0.89)\end{array}$ & $\begin{array}{l}-0.036 \\
(-0.13)\end{array}$ & $\begin{array}{l}0.061 \\
(0.11)\end{array}$ & $\begin{array}{l}0.042 \\
(0.075)\end{array}$ & $\begin{array}{l}-1.43^{* *} \\
(-2.11)\end{array}$ & $\begin{array}{l}-1.350^{*} \\
(-1.91)\end{array}$ & 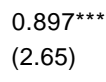 & $\begin{array}{l}1.201 \\
(1.00)\end{array}$ & $\begin{array}{l}0.044 \\
(0.06)\end{array}$ & $\begin{array}{l}-0.380 \\
(-0.92)\end{array}$ \\
\hline R-square & 0.08 & 0.12 & 0.09 & 0.05 & 0.06 & 0.14 & 0.13 & 0.03 & 0.18 & 0.06 & 0.06 \\
\hline $\mathrm{N}$ & 70 & 221 & 228 & 74 & 73 & 48 & 48 & 69 & 23 & 38 & 68 \\
\hline
\end{tabular}

Notes: Same as first two notes in Table 1. Some statistics of openness measures are reported in the text.

regressions. Both INV-OWTI and INV-AVGT are indicators of trade weighted levels of tariffs that come from two different sources. Similarly, INV-OWQI and INV-NTB are two similar measures of quantitative restrictions that come from the same sources. INV-AVGT and INVNTB are not available for industrial countries, while INV-OWTI and INV-OWQI represent both industrial and developing countries. All these four indicators cover only sub periods after the mid 1980s across countries, despite the fact that all the other variables cover the 
period 1980-90. Despite the fact that these four indicators of tariffs and QRs are not significant in medium term growth regressions, the alternative direct measure of openness, TBI, has shown a strong positive association with TFPG rates. TBI is a combination of both import and export taxes averaged over full ten-year periods, whereas all the other direct measures cover only one form of trade restriction for a sub-period between 1985-90.

To check the robustness of the results in relation to import restrictions, an additional regression is run in which trade openness is proxied by the ratio of collected import taxes to total imports (MTAX). The variable INV-MTAX used in the regression is the negative value of MTAX scaled to have zero mean and unit standard deviation to be compatible with the other indicators. In fact, MTAX has been combined with the ratio of export taxes to construct TBI. The result of the regression involving INV-MTAX is reported in column (8) of Table 2. Both TBI and INV-MTAX cover ten-year periods from 1970. The result in the eighth column of this table indicate that import taxes fail to explain cross-country variations of TFPG rates, even though the combination of import and export taxes in TBI has had a significant impact on TFPG growth rates. It implies that the combination of two types of trade restrictions, such as import and export taxes, could make a significant difference in productivity improvements, even though single measures of import restrictions are not significantly associated with growth rates, probably for the following reasons.

First, most of the direct indicators measure only one of several forms of trade restriction at a time. Any single form of restriction alone does not have a significant impact on growth rates. The advantage of TBI over these measures is that it combines both import and export taxes in measuring trade openness. The combination of these two types of trade restriction has clearly made a significant impact on productivity improvements. Second, most of these direct measures are calculated on the basis of trade weighted averages of import restrictions. Higher import restrictions makes the amount of trade across countries lower, underestimating the actual levels of trade barriers in trade weighted averages. A trade restrictiveness index (TRI) introduced by Anderson and Neary (1996) has been defined to overcome this effect of underestimation in trade weighted averages. However, the demand for a large amount of disaggregated data in constructing this index has limited its availability. The regressions in the ninth column of Table 2 have used this index for 23 countries, which does not seem sufficient to draw firm conclusions on the relationship. But the coefficient is large and negative and only just fails to be significant at a 10 percent level.

The regression results in columns (10) and (11) of Table 2 involve two indirect measures of trade openness, namely LEAMER and INV-DOLLAR. Even though these two coefficients have positive signs, they are not highly significant in both regressions. Given the flaws in these indicators, it is difficult to make any firm conclusions based on these measures,. For example, Weerasinghe (1999) finds that the openness index introduced in Dollar (1992) may increase with higher levels of trade restrictions in the form of export taxes. The openness index introduced in Leamer (1988) is based on a gravity model under some unrealistic assumptions.

In summary, the relationship between medium term TFPG rates and trade openness has not been robust in terms of all proxies of trade openness. However, a direct measure (TBI) and two indirect measures (INV-BMP and SWI) have been able to explain variations of TFPG 
rates across countries. All the other indicators are not significant in the regressions.

In comparing these results with others in the literature, the findings in terms of INV-BMP and SWI are consistent with other studies. All similar studies in the literature found a significant relationship between various measures of growth rates and these indicators. In relation to direct indicators, such as levels of tariffs and QRs, the findings are consistent with Bosworth, Collins and Chen (1996). They found no significant relationship between the levels of tariffs and QRs, and their TFPG growth estimates. Because of similar estimation procedures, these TFPG estimates can be directly compared with their estimates. However, in relation to some direct measures, the findings of the present study are not consistent with Edwards (1998), where he finds a strong negative relationship with two similar measures of import restrictions, namely tariff averages and collected import tax ratios. In the present study, the corresponding variables in the regressions are INV-OWTI and INV-MTAX. It appears that the TFPG estimates in Edwards (1998) are significantly different from those in this study. Moreover, Edwards (1998) uses these indicators to explain long term TFP growth rates, whereas this chapter uses them only in the medium term growth regressions.

In terms of other indirect indicators of openness such as INV-DOLLAR and LEAMER, Edwards (1998) finds a significant relationship with one of the openness indexes in Leamer (1988) and TFPG rates. The World Bank (1993) uses the openness index in Dollar (1992) to find a positive correlation between their estimates of TFPG rates and trade openness. In the medium term growth regressions in this study, neither of these indexes are highly significant. However, the other studies have used these indicators to explain cross-country variations in long-term growth rates, despite the fact that these indicators measure trade openness only for shorter time periods in the late 1970s and early 1980s. Openness indexes in Leamer (1988) measure trade openness only for the year 1982. It is less realistic to expect these indicators could explain cross-country variations of TFPG rates across countries over longer time periods.

The differences between TFPG estimates across studies may also contribute to produce these different results. This is probably the main reason for the results of the present study differing from both Edwards (1998) and The World Bank (1993). Weerasinghe and Fane (2005) show that there are significant differences in estimating TFP growth rates across studies in the literature. Hence the relationship between trade openness and TFPG rates appears to depend not only on how trade openness is measured, but also on how TFPG rates are estimated.

\section{Annual time series regressions}

For panel data regressions using pooled annual time series data, two proxies of openness are available, namely INV-BMP and TBI. In these regressions, initial conditions represent the relative levels of income and education in the previous year. Data for INV-BMP are available from 1960 for almost all countries in the sample, making the total number of observations over 2000. For TBI, data are available from the 1970s for a sub-sample of countries, making the total number of observations just over 400. Nevertheless, as reported in Table 3, the results are very similar to the previous findings. 


\section{Table 3 - Panel data TFP growth regressions: Annual time series percentage growth rates}

\begin{tabular}{lcc}
\hline & $(1)$ & $(2)$ \\
\hline$H_{I}^{\max } / H_{I}$ & -0.048 & 0.016 \\
$Y_{I}^{\max } Y_{I}$ & $(-0.72)$ & $(1.24)$ \\
$T B I$ & 0.065 & $-0.022(-1.38)$ \\
& $(1.35)$ & $(-1.38)$ \\
INV-BMP & $0.532^{* *}$ & \\
& $(2.07)$ & $0.688^{* * *}$ \\
Constant & & $(5.81)$ \\
& & 0.239 \\
R-square & -0.670 & $(1.47)$ \\
$N$ & $(-2.17)$ & 0.02 \\
& 0.01 & 2043 \\
\hline
\end{tabular}

Notes:

1. $t$-ratios of regression coefficients are given in parentheses and statistical significance of coefficients is denoted as: $* * * 1 \%$, **5\%., *10\%

2. $\quad N$ - number of observations

3. TBI, and INV-BMP have been scaled so that all have zero mean and unit standard deviations. Mean values of non-scaled TBI, and INV-BMP are -14 and-35, and standard deviations are 12, and 107 percentages respectively

Even in annual time series regressions, both TBI and INV-BMP are significant at one percent level statistical significance. The very low overall explanatory power in terms of Rsquare statistics was expected, because this simple model could hardly explain short-term variations in the residual growth rates. However, this model seems to be satisfactory, for the purpose of testing the relationship between trade openness and growth. There may be several factors other than trade openness that can explain the short-term variations of growth rates. The results suggest that trade openness measured in terms of either of these two indicators is one of the factors that contributes positively towards productivity improvements. In particular, trade openness measured in terms of TBI and INV-BMP appears to have a robust relationship in all situations. For example, an increase in non-scaled TBI of 10 percentage points raises TFP growth by 0.44 percentage points, whereas the corresponding increase in non-scaled INV-BMP raises TFP growth only by 0.06 percentage points. Both of these figures are similar to the figures derived from the previous regressions.

Overall results suggest that the relationship between trade openness and TFP growth remains unchanged across different time periods. The indicators that have been able to explain long-term growth rates are also able to explain variations in annual and medium-term growth rates. Harrison (1996) finds different results between short and long-term GDP growth regressions. However, an indicator based on the BMP is the only common indicator in Harrison (1996) and this study. The result in relation to BMP is consistent in the two studies, because Harrison (1996) finds BMP to be the only significant indicator in all short and long-term regressions, whereas this study makes a similar finding in terms of both TBI and INV-BMP. 


\section{B. Accumulation of physical capital and trade openness}

This section reports the regression results that measure the impact of trade openness on growth in output per worker, through accumulation of physical capital. The dependent variable is the growth rate of physical capital per worker multiplied by the share of capital. It is regressed against the same set of explanatory variables as in TFP growth regressions. Hence the coefficients of these regressions can be directly compared with their counterparts in the TFP growth regressions. The coefficient of trade openness in these regressions can be interpreted as its impact on growth in output per worker, through the channel of physical capital accumulation. The results of long, medium and annual growth regressions are reported.

Table 4 reports the results of the long term growth regressions. The relationship between trade openness and the accumulation of physical capital is strong, particularly in terms of two indirect measures of trade openness, namely INV-BMP and SWI. Both coefficients have expected signs and reject the hypothesis that the true coefficient is zero at high levels of statistical significance.

\section{Table 4 - Long term physical capital growth regressions: Average annual percentage growth rates}

\begin{tabular}{|c|c|c|c|}
\hline & $\begin{array}{c}(1) \\
70-90\end{array}$ & $\begin{array}{c}(2) \\
60-90\end{array}$ & $\begin{array}{c}(3) \\
60-90\end{array}$ \\
\hline$H_{1}^{\max } / H_{1}$ & $\begin{array}{l}-0.098 \\
(-1.37)\end{array}$ & $\begin{array}{l}0.017 \\
(1.33)\end{array}$ & $\begin{array}{l}0.015 \\
(0.89)\end{array}$ \\
\hline$Y_{1}^{\max } / Y_{1}$ & $\begin{array}{l}0.057 \\
(1.07)\end{array}$ & $\begin{array}{l}0.006 \\
(0.39)\end{array}$ & $\begin{array}{c}0.023 \\
(1.44)\end{array}$ \\
\hline$T B I$ & $\begin{array}{l}0.149 \\
(0.81)\end{array}$ & & \\
\hline$I N V-B M P$ & & $\begin{array}{c}0.289^{\star \star * *} \\
(2.76)\end{array}$ & \\
\hline SWI & & & $\begin{array}{c}0.459^{* * *} \\
(4.02)\end{array}$ \\
\hline Constant & $\begin{array}{c}0.800^{\star \star *} \\
(2.76)\end{array}$ & $\begin{array}{c}1.00^{* * *} \\
(6.87)\end{array}$ & $\begin{array}{c}0.820^{\star \star \star *} \\
(6.50)\end{array}$ \\
\hline$R$-square & 0.08 & 0.09 & 0.20 \\
\hline$N$ & 37 & 68 & 75 \\
\hline
\end{tabular}

Notes:

1. $t$-ratios of regression coefficients are given in parentheses and statistical significance of coefficients is denoted as: $* * * 1 \%$, **5\%., *10\%

2. $\quad N$ - number of observations

3. TBI,INV-BMP and SWI have been scaled so that all have zero mean and unit standard deviations. Mean values of non-scaled TBI, INV-BMP and SWI are -12,-35 and 41 and standard deviations are 9, 62 and 45 percentages respectively 
An increase in openness, by moving one standard deviation from its mean, appears to raise growth by 0.3 percentage points, according to the measure based on the black market premium, but by around 0.5 percentage points, according to the specification introduced in Sachs and Warner (1995). An increase in scaled INV-BMP by one unit requires an increase of 60 percentage points in non-scaled INV-BMP. Therefore, a reduction in BMP from ten percentage points would raise the growth component of physical capital accumulation by 0.04 percentage points annually, compared with an increase of 0.06 percentage points through TFP growth. The impact measured in terms of SWI is also lower through physical capital accumulation than through the TFP growth. However, TBI, a direct measure of trade openness based on anti-trade bias, appears to have no significant impact on growth through accumulation of physical capital, even though its impact through the TFP growth is significant. The impact of trade openness in terms of other specifications of openness has been measured using medium term growth regressions, because the other indicators cover shorter time periods. Table 5 reports the results.

The results in medium term growth regressions are consistent with the results of longterm growth regressions in terms of similar indicators. Both INV-BMP and SWI are highly significant and TBI is again not significant. In terms of other direct indicators, namely INVOWTI, INV-OWQI, INV-AVGT and INV-NTB, all are not highly significant in explaining cross-country variations of physical capital accumulation. Only INV-NTB, a measure of quantitative restrictions, has been weakly significant with a t-ratio greater than one. It is an indication that higher levels of quantitative restrictions in trade appear to retard the accumulation of physical capital, thereby the growth in output per worker. This result is not robust, because the other measure of quantitative restrictions is not significant in the regressions. As in the TFP growth regressions, INV-TRI has a negative coefficient with a t-ratio greater than one.

The other two indirect measures of trade openness, namely LEAMER and INV-DOLLAR, have been able to explain cross-country variations of physical capital accumulation at a high level of significance. Both coefficients were not strongly significant in TFP growth regressions. This implies that trade openness, measured in terms of indirect indicators, has a positive impact on growth through accumulation of physical capital. An increase in openness by one standard deviation from its mean appears to raise the growth rate by 0.5 percentage points according to the specification in Leamer (1988), but by 0.3 percentage points according to the specifications of openness in Dollar (1992). However, it is difficult to interpret and compare the results in relation to indirect measures of openness, because their measured units of non-scaled variables are not directly related to trade policy changes. Levine and Renolt (1992) also found that the trade openness index introduced by Leamer (1988) has a strong robust relationship with investment ratio but not with GDP growth.

Table 6 reports the results of annual time-series growth regressions. The dependent variable is annual data on the contribution of physical capital in percentage terms. Explanatory variables are exactly the same as used in the annual TFP growth regressions. Accordingly, both openness measures have been measured in units of standard deviations while the initial conditions are measured in ratios. 
Table 5 - Medium Term Physical Capital Growth Regressions: Average annual percentage growth rates

\begin{tabular}{|c|c|c|c|c|c|c|c|c|c|c|}
\hline & (1) & (2) & (3) & (4) & (5) & (6) & (7) & (8) & (9) & (10) \\
\hline $\mathrm{H}_{1}^{\max } / \mathrm{H}_{1}$ & $\begin{array}{l}-0.024 \\
(-0.27)\end{array}$ & $\begin{array}{l}-0.010 \\
(-0.52)\end{array}$ & $\begin{array}{l}0.006 \\
(0.14)\end{array}$ & $\begin{array}{l}-0.005 \\
(-0.08)\end{array}$ & $\begin{array}{l}-0.008 \\
(-0.12)\end{array}$ & $\begin{array}{l}-0.007 \\
(-0.06)\end{array}$ & $\begin{array}{l}-0.021 \\
(-0.20)\end{array}$ & $\begin{array}{l}-0.254 \\
(-0.82)\end{array}$ & $\begin{array}{l}-0.059 \\
(-0.30)\end{array}$ & $\begin{array}{l}0.069 \\
(1.05)\end{array}$ \\
\hline$Y_{1}^{\max } / Y_{1}$ & $\begin{array}{l}0.010 \\
(0.25)\end{array}$ & $\begin{array}{l}-0.003 \\
(-0.25)\end{array}$ & $\begin{array}{l}0.031 \\
(1.06)\end{array}$ & $\begin{array}{l}-0.023 \\
(-1.15)\end{array}$ & $\begin{array}{l}-0.021 \\
(-1.06)\end{array}$ & $\begin{array}{l}-0.039 \\
-1.32)\end{array}$ & $\begin{array}{l}-0.021 \\
(-0.65)\end{array}$ & $\begin{array}{l}0.029 \\
(0.49)\end{array}$ & $\begin{array}{l}0.097 \\
(1.41)\end{array}$ & $\begin{array}{l}-0.031 \\
(-1.38)\end{array}$ \\
\hline TBI & $\begin{array}{l}0.033 \\
(0.22)\end{array}$ & & & & & & & & & \\
\hline INV-BMP & & $\begin{array}{l}0.353^{\star \star \star} \\
(5.28)\end{array}$ & & & & & & & & \\
\hline SWI & & & $\begin{array}{l}0.762^{\star \star \star} \\
(4.38)\end{array}$ & & & & & & & \\
\hline INV-OWTI & & & & $\begin{array}{l}-0.013 \\
(-0.11)\end{array}$ & & & & & & \\
\hline INV-OWQI & & & & & $\begin{array}{l}0.039 \\
(0.33)\end{array}$ & & & & & \\
\hline INV-AVGT & & & & & & $\begin{array}{l}-0.057 \\
(-0.34)\end{array}$ & & & & \\
\hline INV-NTB & & & & & & & $\begin{array}{l}0.198 \\
(1.03)\end{array}$ & & & \\
\hline INV-TRI & & & & & & & & $\begin{array}{l}-0.395 \\
(-1.23)\end{array}$ & & \\
\hline LEAMER & & & & & & & & & $\begin{array}{l}0.451^{* * *} \\
(3.12)\end{array}$ & \\
\hline INV-DOLLAR & & & & & & & & & & $\begin{array}{l}0.296^{\star \star \star} \\
(2.50)\end{array}$ \\
\hline Constant & $\begin{array}{l}0.913^{\star \star \star} \\
(3.44)\end{array}$ & $\begin{array}{l}1.15^{\star \star \star} \\
(11.45)\end{array}$ & $\begin{array}{l}-0.036 \\
(-0.13)\end{array}$ & $\begin{array}{l}0.75^{\star \star \star} \\
(3.88)\end{array}$ & $\begin{array}{l}0.749^{\star \star \star} \\
(3.82)\end{array}$ & $\begin{array}{l}0.849 \\
(2.31)\end{array}$ & $\begin{array}{l}0.734 \\
(1.96)\end{array}$ & $\begin{array}{l}1.116 \\
(1.71)\end{array}$ & $\begin{array}{l}0.558 \\
(1.91)\end{array}$ & $\begin{array}{l}0.513^{\star \star \star} \\
(2.71)\end{array}$ \\
\hline R-square & 0.00 & 0.11 & 0.09 & 0.04 & 0.04 & 0.06 & 0.07 & 0.11 & 0.24 & 0.12 \\
\hline $\mathrm{N}$ & 70 & 221 & 228 & 74 & 73 & 48 & 48 & 23 & 38 & 68 \\
\hline
\end{tabular}

Notes:

1. $t$-ratios of regression coefficients are given in parentheses and statistical significance of coefficients is denoted as: $* * * 1 \%$, **5\%., *10\%

2. $\quad N$ - number of observations 
Table 6 - Panel data physical capital growth regressions: Annual time series percentage growth rates

\begin{tabular}{lcc}
\hline & $(1)$ & $(2)$ \\
\hline$H_{I}^{\text {max }} / H_{l}$ & 0.026 & $0.006^{* \star}$ \\
& $(1.27)$ & $(2.17)$ \\
$Y_{I}^{\max } Y_{I}$ & -0.026 & $-0.013^{\star \star \star}$ \\
& $(-1.75)$ & $(-3.74)$ \\
$T B I$ & -0.131 & \\
INV-BMP & $(-1.64)$ & $0.288^{\star \star \star}$ \\
Constant & & $(10.34)$ \\
& & $1.217^{\star \star \star}$ \\
R-square & $1.144^{\star \star \star}$ & $(31.78)$ \\
$N$ & $(11.81)$ & 0.07 \\
\hline
\end{tabular}

Notes:

1. $t$-ratios of regression coefficients are given in parentheses and statistical significance of coefficients is denoted as: $* * * 1 \%$, **5\%., $* 10 \%$

2. $\quad N$ - number of observations

3. TBI, and INV-BMP have been scaled so that all have zero mean and unit standard deviations.

Mean values of non-scaled TBI, and INV-BMP are -13 and -37, and standard deviations are 12 , and 108 percentages respectively

The results in relation to both measures of openness are almost similar to the results derived from long and medium term growth regressions. INV-BMP is highly significant with the expected sign, but the coefficient of TBI is negative and just close to being somewhat significant at the ten percent level. Its coefficient, -0.131 , is small compared with the corresponding coefficient of 0.532 , in annual TFP growth regressions.

In comparison with the impact of openness through TFP growth and physical capital accumulation, four indirect measures of openness have been significant in physical capital growth regressions compared with two indirect measures of openness through TFP growth regressions. However, in terms of direct measures, TBI is significant only in the TFP growth regressions. In addition, its measured impact on the TFP growth is much higher than that measured in terms of indirect indicators.

\section{Accumulation of human capital and trade openness}

The same set of explanatory variables is also regressed against the contribution of human capital $\left(Y_{H}\right)$. As expected, none of the indicators of openness are strongly significant in both the long and medium term growth regressions. Table 7 reports the results of long-term growth regressions. Only the coefficient of TBI has a t-ratio greater than one, but the estimated coefficient is very small compared with the correspondent coefficients in the previous regressions. All the other coefficients are not at all significant in all regressions, including medium term growth regressions. The results of the medium term growth regres- 


\section{Table 7 - Long term human capital growth regressions: Average annual percentage growth rates}

\begin{tabular}{lccc}
\hline & $(1)$ & $(2)$ & $(3)$ \\
\hline$H_{1}^{\max / H_{1}}$ & 0.026 & 0.010 & 0.027 \\
$Y_{1}^{\max / Y_{1}}$ & $(3.18)$ & $(1.43)$ & $(1.02)$ \\
& -0.004 & -0.006 & 0.015 \\
TBI & $(-0.50)$ & $(-0.72)$ & $(1.46)$ \\
INV-BMP & & & 0.071 \\
SWI & & & $(1.45)$ \\
& 0.029 & & \\
Constant & $(0.89)$ & & \\
& & -0.012 & \\
R-square & & $(-0.33)$ & 0.303 \\
$\mathrm{~N}$ & 0.381 & 0.439 & $(3.33)$ \\
\hline
\end{tabular}

Notes:

1. $t$-ratios of regression coefficients are given in parentheses and statistical significance of coefficients is denoted as: $* * * 1 \%, * * 5 \%$., $* 10 \%$

2. $\quad N$ - number of observations

sions are reported in Appendix Table 2. These results indicate that trade openness has no significant impact on human capital accumulation.

\section{Comparison between three channels}

To compare the impacts of trade openness through three components of growth, Table 8 summarizes some estimated coefficients of three indicators of trade openness, namely TBI, INV-BMP and SWI. These are the indicators that were mostly significant, particularly in TFP and physical capital growth regressions. The growth accounting identity specified in equation (5) allows the three estimated coefficients to be added up to calculate the total impact of trade openness on growth in output per worker. The fourth column of the Table 8 reports these calculations.

Comparing the impact of trade openness through two major channels, the figures in the first and second columns suggest that trade openness affects economic growth more through the channel of productivity improvements than through physical capital accumulation. The estimated coefficients in TFP growth regressions are higher in terms of all measures of trade openness. Nevertheless, the impact through the accumulation of physical capital is also significant, particularly in terms of INV-BMP and SWI.

In terms of unit standard deviations, the total impact of openness on output per worker growth is highest according to the specifications of SWI and lowest in terms of TBI, as 
shown in the fourth column of Table 8. The fifth column of the table shows the increase of growth in output per worker in response to an increase in each non-scaled openness measure by 10 percentage points. According to these figures, the TBI's impact is significantly higher than the impact of the other two measures for a similar increase in percentage points. An increase in the TBI, for example from -20 percent to -10 percent, would raise annual growth in output per worker by 0.612 percentage points, whereas a ten percent reduction in the BMP would raise annual growth in output per worker by only 0.118 percentage points. In this study, TBI is a direct indicator which measures the relative price difference between export and import-competing goods, thereby related to the welfare losses of trade restrictions. On the other hand, BMP, and to a lesser extent SWI, are probably correlated with things like financial repression and macro mismanagement, which also retard growth.

Interpretation of the result in relation to SWI suggests that if a country increased its ratio of number of years open to total years by ten percentage points, that country's annual growth in output per worker could be raised by 0.24 percentage points. However, the classification of a country's openness in SWI, makes it difficult to directly link the result with specific policy matters.

Comparing of results with the other studies, Bosworth and Collins (1996) find that the Sachs-Warner openness index is strongly associated with capital accumulation, but its association with productivity improvements is weaker. This finding is not consistent because this study finds that the SWI is strongly associated with both sources of growth. Because it is an indirect measure, Bosworth and Collins (1996) are also reluctant to draw any firm conclusions based on the SWI. However, the present study finds that a direct measure of openness, the TBI, is increasingly associated with TFPG rather than with the accumulation

\section{Table 8 - Comparison of the impact of openness through different compmonents of growth}

\begin{tabular}{|c|c|c|c|c|c|c|}
\hline Openness & $\begin{array}{c}Y_{A}(T F P G) \\
(1)\end{array}$ & $\begin{array}{l}Y_{K} \\
(2)\end{array}$ & $\begin{array}{l}Y_{H} \\
(3)\end{array}$ & $\begin{array}{l}Y \\
\text { (4) }\end{array}$ & $\begin{array}{c}Y(10 \%) \\
(5)\end{array}$ & $\begin{array}{c}\text { Std-dev of } \\
\text { openness (\%) }\end{array}$ \\
\hline TBI & $\begin{array}{r}0.331^{*} \\
(1.83)\end{array}$ & $\begin{array}{l}0.149 \\
(0.81)\end{array}$ & $\begin{array}{l}0.071 \\
(1.46)\end{array}$ & 0.551 & 0.612 & 9 \\
\hline INV-BMP & $\begin{array}{c}0.395^{\star * *} \\
(3.24)\end{array}$ & $\begin{array}{c}0.289^{\star * *} \\
(2.76)\end{array}$ & $\begin{array}{l}0.029 \\
(0.89)\end{array}$ & 0.713 & 0.118 & 60 \\
\hline SWI & $\begin{array}{c}0.635^{* * *} \\
(4.57)\end{array}$ & $\begin{array}{c}0.459^{* * *} \\
(4.02)\end{array}$ & $\begin{array}{l}-0.012 \\
(-0.33)\end{array}$ & 1.082 & 0.240 & 45 \\
\hline
\end{tabular}

Notes:

1. $t$-ratios of regression coefficients are given in parentheses and statistical significance of coefficients is denoted as: $* * * 1 \%$, **5\%., *10\%.

2. The results in the first four columns are based on openness measured in units of standard deviations.

3. The result in the fifth column indicates the change in output per worker in response to a ten percent increase in each non-scaled openness measure.

4. The last column indicates the standard deviation of each non-scaled openness measure. These numbers were used to scale openness measures to be measured in units of std-deviations. 
of physical capital, indicating that openness operates more strongly through productivity improvements than though the accumulation of physical capital. In their regression analysis, Bosworth and Collins (1996) introduced some extra variables to represent macroeconomic policies and external conditions. In addition, they introduced region-specific dummy variables for five regions, namely East Asia, industrial countries, Latin America, South Asia, Middle East and Africa. The introduction of regional dummy variables appears to have made the relationship between the Sachs-Warner index and productivity growth weaker. It is difficult to make economic interpretations of the coefficients of region specific dummy variables, because countries within a region have more differences than similarities. Geographical groupings may have little relevance in explaining cross-country variations in economic growth rates. If necessary, groupings of countries according to their income or levels of education may be more appropriate.

The results in Bosworth, Collins and Chen (1996) are consistent with the present study, in the sense that they find no significant correlation between levels of tariffs and QRs, and any component of growth. However, this finding is not consistent with Edwards (1998), where he finds a robust relationship between direct measures of trade openness and TFP growth. The different TFPG estimates in the two studies have probably produced inconsistent results.

\section{Summary and conclusions}

It is found that the relationship between trade openness and TFP growth is not robust to all alternative indicators of trade openness. The relationship depends mainly on two factors: a) the measurement of trade openness, and b) the estimates of TFPG rates. If trade openness is measured using the concept called anti-trade bias, the relationship between openness and TFP growth is positive and significant. Even though individual indicators of tariffs and NTBs are direct measures of trade restrictions, any single type of many trade restrictions still fails to explain cross-country variations of economic growth rates. The inconsistent results in the literature on the relationship between these direct measures of openness and TFP growth arises mainly from different estimates of TFPG. Two other indirect measures of trade policy, namely BMP and the Sachs-Warner index, have also shown a strong positive association with productivity improvements. In terms of these two indicators, trade restrictions also appear to retard the accumulation of physical capital and thereby output growth, but to a lesser extent than through productivity improvements. Based on the findings related to both direct and indirect measures of trade openness, the major channel of effectiveness of openness operates through TFPG. There is also evidence that, if there is any positive impact of trade openness on output growth, it operates consistently in both the short and longterm. Accounting for short-term variations of growth rates has not produced results any different from the results of medium and long-term variations of economic growth. 


\section{References}

Anderson, James E. (1998) “Trade Restrictiveness Benchmarks”, The Economic Journal, 108 (July):1111-1125

Anderson, James E. and Peter J. Neary (1996), “A New Approach to Evaluating Trade Policy”, Review of Economic Studies, 63:107-25.

Barro, Robert, J. and Jong-Wha Lee (1994), “Data set for a Panel of 138 countries', on line data at http://www.nber.org/pub/barro.lee/

Ben-David, Dan (1993), "Equalizing Exchange: Trade Liberalization and Income Convergence", Quarterly Journal of Economics, 108(3).

Bhagwati, J.N. (1978), "Foreign Trade Regimes and Economic Development: Anatomy and consequences of exchange control regimes", Cambridge, MA: Ballinger Pub. Co. for NBER.

Bosworth Barry and Susan M. Collins (1996), "Economic growth in Asia: Accumulation versus Assimilation', Brookings Papers on Economic Activity, 2, pp. 135-203.

Bosworth, Barry, Susan M. Collins and Yu-chin Chen (1996), "Accounting for Differences in Economic Growth", In Structural Adjustment and Economic Reform: East Asia, Latin America, and Central and Eastern Europe, edited by Akira Kohsaka and Koichi Ohno, Tokyo: Institute of Developing Economies.

Dollar, David (1992), “Outward-Oriented Developing Economies Really Do Grow More Rapidly: Evidence from 95 LDCs, 1976-85”, Economic Development and Cultural Change, 40(3):523-44

Edwards, Sebastian (1992), “Trade Orientation, Distortions, and Growth in Developing Countries", Journal of Development Economics, 39(1): 31-57.

Edwards, Sebastian (1993), "Openness, trade liberalization, and growth in developing countries”, Journal of Economic Literature, Vol. XXXI (September 1993):1358-1393.

Edwards, Sebastian (1998), “ Openness, Productivity and Growth: What do we really know?" The Economic Journal, March:383-398.

Harrison, Ann (1996), “Openness and Growth: A time-series, cross country analysis for developing countries", Journal of Development Economics, 48(2):419-447. 
Krueger, Anne O. (1978), "Foreign Trade Regimes and Economic Development: Liberalization Attempts and consequences", Cambridge, MA: Ballinger Pub. Co. for NBER.

Krueger, Anne O. (1978), "Foreign Trade Regimes and Economic Development: Liberalization Attempts and consequences", Cambridge, MA: Ballinger Pub. Co. for NBER.

Leamer, E. E. (1988), “Measures of openness" In Trade policy issues and empirical analysis. National Bureau of Economic Research Conference Report series, edited by Baldwin, Robert E.,Chicago and London: University of Chicago Press, 1988:147-200.

Levine, Ross and David Renelt (1992), “A Sensitivity Analysis of Cross-Country Growth regressions", American Economic Review 82(4):942-63.

Neruh, Vikram and Ashok Dhareshwar (1994), "New Estimates of Total Factor Productivity Growth for Developing and Industrial Countries”, Policy Research Working Paper 1313, Washington: World Bank.

Prichett, Lant (1996), "Measuring Outward Orientation in LDCs: Can it be done", Journal of Development Economics, 49:307-335.

Rodrik, Dani and Francisco Rodriguez (1999). "Trade Policy and Economic Growth: A Skeptic's Guide to Cross-National Evidence”, National Bureau of Economic Research Working Paper 7081.

Sachs, J. and Warner, A. (1995), "Economic Reform and the Process of Global Integration”, Brookings Papers on Economic Activity, 1, pp. 1-118.

The World Bank (1993), “The East Asian Miracle: Economic growth and public policy”, A World Bank Policy Research Report, Oxford University Press, New York.

UNCTAD (1988), Handbook of Trade Control Measures of Developing Countries supplement: A statistical analysis of trade control measures of developing countries, UNCTAD/DDM GE.89-55071, Geneva.

Weerasinghe, P. Nandalal and Fane, George (Forthcoming 2005) 'Discrepancies in Total Factor Productivity Growth in East Asia', Economic Papers. The Economic Society of Australia, Inc.

Weerasinghe, P.Nandalal (1999), 'Trade Policy Openness and Economic Performance: Cross-Country Evidence', Unpublished Thesis, Australian National University. 


\section{Appendix .1: Alternative indicators of trade openness}

A brief description of the indicators of trade openness used in this study is given below. The original measures of openness have been scaled so that all have zero means and unit standard deviation, thereby all estimated coefficients have a common interpretation in the units of standard deviations. In addition, the original indexes have been inverted if they originally measure the restrictiveness of trade policy. For example, INV-BMP represents the negative of the original black market premium (BMP). The purpose of this kind of notation is to help identify the original source by its familiar notation. Accordingly, if the relationship between trade openness and the dependent variables is positive, a positive coefficient would be expected in the estimated coefficient. The sources of data, their coverage, and definitions are given below. All non scaled variables are measured in percentage rates.

INV-OWTI : Own-import weighted average tariffs on imports of intermediates and capital goods. Data comes from Barro and Lee (1994) who rely on UNCTAD data. Period covered is 1985-88. The non-scaled variable is the negative value of the original variable measured in percentage rates.

INV-OWQI: Own-import weighted nontariff frequency on capital goods and intermediates. The coverage and the source of data are exactly the same as OWTI. The non-scaled variable is the negative value of the original variable measured in percentage rates.

INV-AVGT: The source is Pritchett (1996) who calculated weighted averages of total import charges in percentage rates, which includes tariffs, duties and custom fees etc. 1985 world imports have been used as weights. The primary source of data is UNCTAD (1988). Data are available only for a sample of developing countries. The period covered for each country ranges from 1985-88. The non-scaled variable is the negative value of the original variable.

INV-NTB: Data on coverage ratio of non-tariff barriers also from Prichett (1996). Measured as the import weighted percent of tariff code lines within the aggregate. Weights and period covered similar to AVGT. The non-scaled variable is the negative value of the original variable.

INV-DOLLAR: The index of real exchange rate distortion introduced in Dollar (1992) covers the period 1976-85 on average. In Dollar (1992), this has been defined as the ratio of domestic price level to US price level. The non-scaled variable is the inverse of the original price ratio multiplied by 100 .

LEAMER - adjusted trade intensity ratio constructed in Leamer (1988) using a gravity model. His openness index measures the difference between predicted trade intensity ratio and actual trade intensity ratio. The trade intensity ratio has been defined as the ratio of imports plus exports to GNP. Leamer's index measures openness for the year 1982. Since the original measure is expected to increase with openness the non-scale variable is simply the percentage of the original variable.

SWI: Data from Sachs and Warner (1995) categorizes countries as opened or closed. They also identify the year when a country changed its stance from closed to open, or vice versa. 
This study constructs the percentage of years open to total years during the period for each country. In the long-term measure of openness, total number of years covers the period 1960-90. For the medium term measure of openness, total number of years covers ten-year time periods. For example, a country is assigned the value zero if it has been classified as closed throughout the time period. If half of the period is open according to the classification, SWI takes the value of 50.

INV-BMP: - The original black market premium (BMP) in Barro and Lee (1994) has been defined as the ratio of black market exchange rate to the official exchange rate minus one. They provide six series of five-year averages of black market premium for the periods starting from 1960-64 to 1985-89. The INV-BMP here is the percentage rate of negative BMP.

TBI: Trade bias index is defined as;

$$
100+\mathrm{TBI}=100\left[\frac{1-t_{x}}{1+t_{m}}\right]
$$

where $t_{x}$ and $t_{m}$ are ratios of collected export taxes to total exports, and the ratio of collected import taxes to total imports respectively. This concept comes from the definition of antitrade bias (ATB) introduced by Bhagwati (1978) and Krueger (1978). Annual data for $t_{x}$ and $t_{m}$ come from the International Economic Data Bank at the Australian National University, which relies on World Bank data. Annual data are available for a group of countries from the 1970s. It is important to note that $100+\mathrm{TBI}$ is the inverse of $100+\mathrm{ATB}$ and thereby measures trade policy openness.

INV-TRI: Data from Anderson (1998) provides tariff equivalent estimates of trade restrictiveness index for a sample of 28 countries. The non-scaled variable is the negative value of the original variable in percentage rates. 
Appendix Table 1: Sources of growth: Average annual growth rates (\%)

\begin{tabular}{|c|c|c|c|c|c|}
\hline & & $1960-$ & & & $1960-87$ \\
\hline & $Y$ & $Y_{K}$ & $Y_{H}$ & $Y_{A}$ & $Y_{A}$ \\
\hline \multicolumn{6}{|l|}{ East Asia } \\
\hline China & 3.35 & 1.22 & - & - & 1.77 \\
\hline Indonesia & 3.20 & 1.87 & 1.16 & 0.17 & 0.08 \\
\hline Korea, Rep of & 5.71 & 2.73 & 1.41 & 1.56 & 1.51 \\
\hline Malaysia & 3.49 & 3.00 & 0.52 & -0.03 & -0.57 \\
\hline Philippines & 1.49 & 1.36 & 0.44 & -0.31 & -0.57 \\
\hline Singapore & 4.93 & 4.87 & 0.35 & -0.30 & -1.77 \\
\hline Taiwan & 5.68 & 2.33 & 0.61 & 2.74 & - \\
\hline Thailand & 4.64 & 2.69 & 0.28 & 1.67 & 0.94 \\
\hline \multicolumn{6}{|c|}{ Industrial Countries } \\
\hline Australia & 1.57 & 1.04 & 0.15 & 0.37 & 0.37 \\
\hline Austria & 3.29 & 2.14 & 0.70 & 0.45 & 0.96 \\
\hline Belgium & 2.76 & 0.73 & 0.23 & 1.81 & 1.77 \\
\hline Canada & 1.76 & 0.64 & 0.02 & 1.10 & 1.06 \\
\hline Denmark & 1.84 & 0.87 & 0.12 & 0.85 & 0.79 \\
\hline Finland & 2.98 & 1.55 & 0.28 & 1.15 & 0.90 \\
\hline France & 2.81 & 0.98 & 0.56 & 1.27 & 1.70 \\
\hline Germany & 2.67 & 1.22 & 0.10 & 1.36 & 1.42 \\
\hline Greece & 3.99 & 1.88 & 0.19 & 1.91 & 2.08 \\
\hline Iceland & 2.09 & 0.84 & 0.38 & 0.87 & 1.19 \\
\hline Ireland & 3.20 & 1.36 & 0.27 & 1.58 & - \\
\hline Italy & 3.43 & 1.15 & 0.10 & 2.18 & 2.23 \\
\hline Japan & 5.03 & 1.79 & 0.20 & 3.04 & 3.09 \\
\hline Luxembourg & 2.51 & 1.09 & - & - & - \\
\hline Netherlands & 1.77 & 0.70 & 0.64 & 0.42 & 0.95 \\
\hline New Zealand & 0.52 & 0.60 & 0.23 & -0.30 & -0.40 \\
\hline Norway & 2.25 & 0.55 & 0.47 & 1.23 & 1.87 \\
\hline Portugal & 3.41 & 1.97 & 0.43 & 1.02 & 0.83 \\
\hline Spain & 3.69 & 2.02 & 0.47 & 1.20 & 1.35 \\
\hline Sweden & 1.83 & 1.32 & 0.17 & 0.35 & 0.46 \\
\hline Switzerland & 1.72 & 1.23 & 0.38 & 0.11 & 0.52 \\
\hline Turkey & 3.41 & 1.36 & 0.52 & 1.53 & 1.34 \\
\hline United Kingdom & 1.94 & 0.72 & 0.16 & 1.06 & 1.19 \\
\hline United States & 1.38 & 0.27 & 0.85 & 0.26 & 0.84 \\
\hline \multicolumn{6}{|l|}{ Latin America } \\
\hline Argentina & 0.69 & 0.81 & 0.31 & -0.43 & -0.09 \\
\hline Bolivia & 0.60 & 0.34 & -0.08 & 0.33 & -0.46 \\
\hline Brazil & 2.32 & 0.93 & 0.34 & 1.05 & 1.07 \\
\hline Chile & 0.98 & 0.24 & 0.38 & 0.37 & -0.04 \\
\hline Colombia & 1.92 & 0.36 & 0.55 & 1.01 & 0.76 \\
\hline Costa Rica & 1.18 & 1.29 & 0.30 & -0.41 & -0.79 \\
\hline Dominican Rep & 1.82 & 1.17 & 0.39 & 0.25 & - \\
\hline Ecuador & 2.15 & 0.73 & 0.66 & 0.75 & 0.73 \\
\hline El Salvador & -0.16 & 0.66 & 0.32 & -1.14 & -1.48 \\
\hline Guatemala & 1.41 & 0.52 & 0.56 & 0.33 & 0.36 \\
\hline Guyana & -2.22 & -0.33 & 0.30 & -2.19 & - \\
\hline Haiti & -0.20 & 1.09 & 0.52 & -1.81 & -1.34 \\
\hline Honduras & 0.90 & 0.56 & 0.91 & -0.57 & -0.48 \\
\hline Jamaica & -0.27 & 0.16 & 1.31 & -1.74 & -2.35 \\
\hline Mexico & 1.53 & 1.32 & 1.11 & -0.89 & -0.50 \\
\hline $\begin{array}{l}\text { Nicaragua } \\
\text { (Continued) }\end{array}$ & -1.35 & 0.66 & 0.30 & -2.32 & - \\
\hline
\end{tabular}


Appendix Table 1 (Continued)

\begin{tabular}{|c|c|c|c|c|c|}
\hline & & $1960-5$ & & & $1960-87$ \\
\hline & $Y$ & $Y_{K}$ & $Y_{H}$ & $Y_{A}$ & $Y_{4}$ \\
\hline Panama & 1.73 & 1.52 & 0.91 & -0.70 & $-{ }^{A} .06$ \\
\hline Paraguay & 2.18 & 1.60 & 0.35 & 0.24 & 0.22 \\
\hline Peru & -0.11 & 0.35 & 0.51 & -0.98 & 0.10 \\
\hline Trinidad and Tobago & 0.25 & 1.29 & 0.40 & -1.43 & - \\
\hline Uruguay & 0.77 & 0.19 & 0.34 & 0.24 & -0.06 \\
\hline Venezuela & -0.88 & -0.03 & 0.42 & -1.27 & -1.67 \\
\hline $\begin{array}{l}\text { Middle East } \\
\text { and North Africa }\end{array}$ & & & & & \\
\hline Algeria & 1.25 & 0.82 & 0.87 & -0.44 & 0.01 \\
\hline Cyprus & 4.58 & 1.56 & 0.54 & 2.48 & 2.41 \\
\hline Egypt, Arab Rep & 3.70 & 1.91 & - & - & 1.43 \\
\hline Iran, Islamic Rep & 1.34 & 1.61 & 0.87 & -1.14 & -1.21 \\
\hline Iraq & -1.11 & 1.56 & 0.82 & -3.48 & -3.45 \\
\hline Israel & 2.84 & 0.84 & 0.30 & 1.69 & 1.42 \\
\hline Jordan & 1.02 & 1.97 & 0.87 & -1.82 & -1.45 \\
\hline Kuwait & -5.65 & 0.93 & 0.28 & -6.86 & - \\
\hline Libya & 1.72 & 2.83 & - & - & - \\
\hline Malta & 4.81 & 1.74 & - & - & - \\
\hline Morocco & 2.21 & 0.85 & - & - & 0.57 \\
\hline Tunisia & 2.34 & 1.10 & 0.54 & 0.69 & 0.64 \\
\hline South Asia & & & & & \\
\hline Bangladesh & 1.13 & 0.28 & 0.39 & 0.47 & 0.55 \\
\hline India & 2.41 & 1.08 & 0.26 & 1.07 & 0.78 \\
\hline Myanmar & 0.91 & 0.56 & 0.33 & 0.02 & 0.33 \\
\hline Pakistan & 3.34 & 1.77 & 0.73 & 0.84 & 1.23 \\
\hline Sri Lanka & 2.35 & 1.46 & 0.30 & 0.59 & 0.58 \\
\hline Sub-Sahara Africa & & & & & \\
\hline Angola & -0.14 & 0.48 & - & - & -1.42 \\
\hline Cameroon & 2.08 & 1.66 & 0.34 & 0.09 & 0.49 \\
\hline Cote dlvoire & 2.37 & 1.47 & - & - & 0.45 \\
\hline Ethiopia & 0.87 & 1.31 & - & - & -0.27 \\
\hline Ghana & -0.42 & 0.39 & 0.50 & -1.31 & -1.72 \\
\hline Kenya & 1.99 & -0.21 & 0.72 & 1.48 & 1.20 \\
\hline Madagascar & -0.57 & 0.23 & - & - & -1.38 \\
\hline Malawi & 2.01 & 1.67 & 0.19 & 0.15 & 0.15 \\
\hline Mali & 1.25 & 0.46 & 0.13 & 0.66 & 0.57 \\
\hline Mauritius & 2.18 & 0.04 & 0.53 & 1.61 & 1.37 \\
\hline Mozambique & -0.66 & 0.54 & 0.11 & -1.31 & -2.13 \\
\hline Nigeria & 0.07 & 1.14 & - & - & -2.33 \\
\hline Rwanda & 0.05 & 1.11 & - & - & -0.96 \\
\hline Senegal & -0.02 & -0.01 & 0.13 & -0.15 & -0.53 \\
\hline Sierra Leone & 1.69 & 0.96 & 0.37 & 0.36 & 0.25 \\
\hline South Africa & 1.12 & 0.96 & 0.26 & -0.10 & - \\
\hline Sudan & -0.43 & 1.43 & 0.27 & -2.13 & -2.29 \\
\hline Tanzania & 1.09 & 0.42 & -0.19 & 0.86 & -0.02 \\
\hline Uganda & -2.44 & -0.03 & 0.15 & -2.55 & -3.37 \\
\hline Zaire & 0.03 & 0.40 & 0.51 & -0.87 & -0.82 \\
\hline Zambia & -0.83 & -0.56 & 0.47 & -0.75 & -1.19 \\
\hline Zimbabwe & 1.18 & 0.02 & 0.45 & 0.71 & 0.41 \\
\hline
\end{tabular}




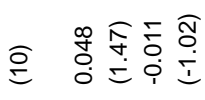

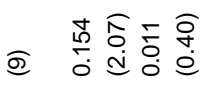

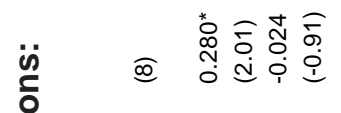

की

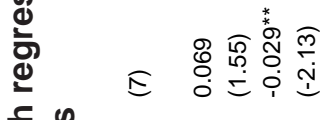

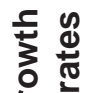

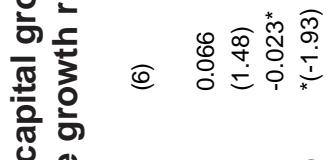

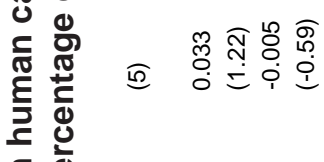

돈 일

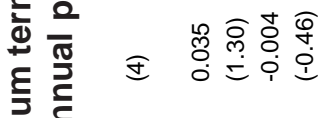

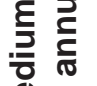

$\stackrel{0}{2}$

N

$\frac{0}{0}$

풍

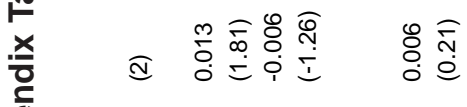

ఫ.

은

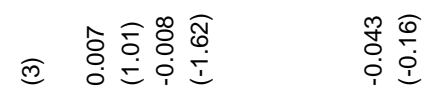

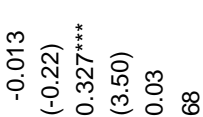

응

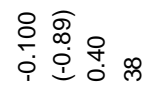

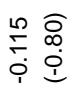

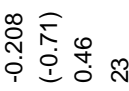

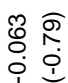

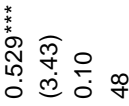

fo
\&
0
0

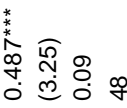

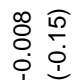

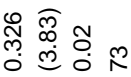

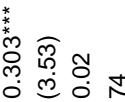

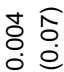

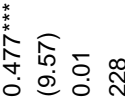

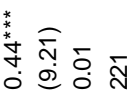

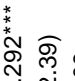

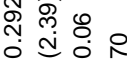

$\frac{\stackrel{8}{0}}{2}$

$\frac{50}{*}$

$\ddot{3}$

(1)

ป

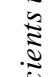

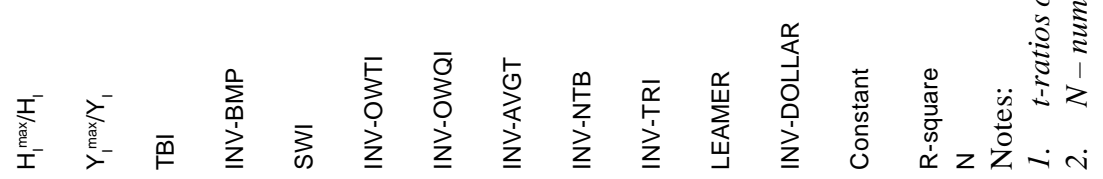

